DOI: https://doi.org/10.24867/14BE21Markovic

\title{
PROSTORNE KARAKTERISTIKE ZVUKA I RAZLIKE IZMEĐU BINAURALNE I STEREO REPRODUKCIJE
}

\section{SPATIAL CHARACTERISTICS OF SOUND AND THE DIFFERENCE BETWEEN BINAURAL AND STEREO REPRODUCTION}

\section{Milan Marković, Fakultet tehničkih nauka, Novi Sad}

\begin{abstract}
Oblast - ELEKTROTEHNIKA I RAČUNARSTVO
Kratak sadržaj - U radu se opisuje binauralna tehnologija, njeno razlikovanje od stereofonskog koncepta, kao $i$ studijske tehnike snimanja i reprodukcije snimaka načinjenih veštačkom glavom
\end{abstract}

Ključne reči: Binauralna tehnologija, stereofonija, veštačka glava

\begin{abstract}
The paper describes: studio techniques of recording and reproducing audio signals made with an artificial head, differences between stereophony and binaural and details about electroacoustic signal reproduction.
\end{abstract}

Keywords: Binaural, stereophony, artificial head, dummy head

\section{UVOD}

Sve češće se susrećemo sa sintagmom - virtuelna realnost. Često je prva asocijacija na tu sintagmu nekakva vizelna tehnologija. Međutim, snimanje i reprodukcija zvučnih signala je, takođe, nešto što je prilično akutelno. Ideja da se zvučni signali predstave na takav način da verno opišu jedan zvučni događaj je stara stotinama godina unazad, a tek danas imamo odgovarajuću tehniku i tehnologiju da je akutelizujemo na pravi način. Da bi se to postiglo, razvijeno je nekoliko tehnika, kao što su stereofonske i binauralne tehnike snimanja i reprodukcije. Popularizacijom interneta porastao je broj binauralnih sadržaja i interesovanje za njih. Može se reći da binauralni koncept predstavlja najdirekntiji pokušaj prenosa prostornih informacija. Kompanije se godinama utrkuju koja će da napravi najbolju veštačku glavu, a nesvesno konvergiraju ka standardizovanom konceptu.

U ovom radu ćemo se upoznati sa osnovama binauralnog snimanja i reprodukcije, sa prostornim karakteristika zvuka i elektroakustičkom reprodukcijom zvučnih signala.

\section{PROSTORNE KARAKTERISTIKE ZVUKA}

Naše čulo sluha je veoma moćno čulo, pomaže nam da komuniciramo sa drugim ljudima i prirodom, prepoznamo opasnost, da sarađujemo i uživamo u raznim zvukovima.

\section{NAPOMENA:}

Ovaj rad proistekao je iz master rada čiji mentor je bio dr Vlado Delić, red. prof.
Ali ono što je takođe bitno jesto to da pomoću čula sluha mi imamo mogućnost da odredimo pravac, udaljenost $\mathrm{i}$ dimenzije nekog zvučnog izvora.

Prostorno razlikovanje i prepoznavanje izvora nazivamo prostorno slušanje, a sposobnost koja nam to omogućava zovemo - binauralna lokalizacija.

Kao što smo rekli, pomoću čula sluha, možemo da odredimo poziciju izvora zvuka u 3D prostoru. Uši možemo smatrati senzorima zvuka prostorno razmaknutim, a glavu preprekom između njih. To predstavlja nekakvu fizičku postavku za - binauralno (prostorno) slušanje.

Zahvaljujući binauralnom slušanju čulo sluha ima sposobnost određivanja pravca iz koje zvučni talas nailazi.

Uvešćemo koordinantni sistem glave slušaoca i definisaćemo horizontalnu, medijalnu i frontalnu ravan slušaoca, a sve moguće pravce i smerove nailaska talasa na glavu slušaoca odredićemo azimutom $\Phi$ i elevacijom $\delta$, baš kao na Ilustraciji 1, kako bismo se bolje snašli u nastavku.

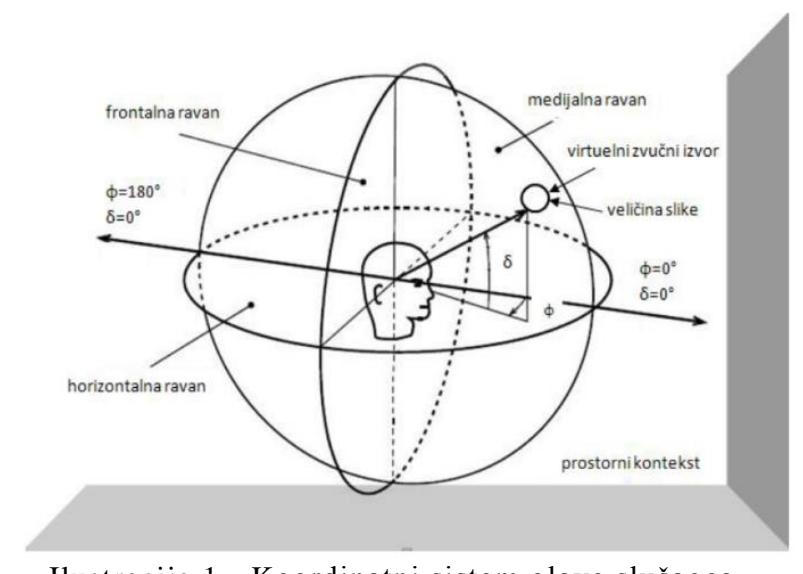

Ilustracija 1 - Koordinatni sistem glave slušaoca

\subsection{Određivanje pravca, udaljenosti i dimenzija zvučnog izvora}

Da bismo odredili pravac nekog zvučnog izvora možemo iskoristiti nekoliko poznatih metoda.

Jedna je određivanje pravac pomoću razlike $u$ intenzitetu zvuka. Osećaj pravca pomoću razlike u intenzitetu zvukova na mestu jednog i drugog uha [1], detektuje se uz pomoć ukrštenih nervnih puteva između oba uha. Samo dva pravca daju istu intezitetnu razliku. To su pravci $0^{\circ} \mathrm{i}$ $180^{\circ}$. Govorimo o horizontalnoj ravni. Ovaj mehanizam detektuje podatak o razlici intenziteta, upoređivanjem anvelopa složenog signala $u$ jednom i drugom uhu. Intenzitetna razlika bližeg $i$ daljeg uha se naziva - 
interauralna intezitetska razlika [2] (ILD - engl. Interaural Level Difference), koja je ilustrovana na ilustraciji 2. Na ilustraciji je prikazana razlika u intenzitetu zvuka koju osete uši kada zvučni izvor nije postavljen na pravcu od $0^{\circ}$ ili $180^{\circ}$. Zvuk mora da pređe veću razdaljinu, pa oslabi, a i oslabi zbog filtarskog efekta glave.

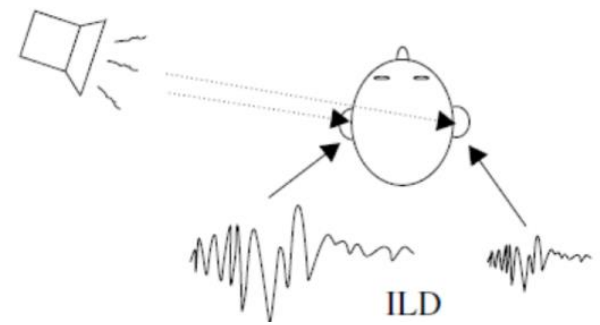

Ilustracija 2 - Intenzitetska razlika

Pokazalo se da glava ima filtarski efekat na stanje $u$ zvučnom polju. I za kvantifikovanje tog efekta uvedena je veličina koja se naziva - funkcija prenosa glave (HRTF engl. Head Related Transfer Function). Ona pokazuje promene signala na levom i desnom uhu u odnosu na stanje u zvučnom polju kada slušalac nije prisutan.

Drugi metod je: određivanje pravca pomoću vremenske razlike. Vremenska razlika signala bližeg i daljeg uha naziva se - interauralno kašnjenje (ITD-engl. Interaural Time Difference). Sa Ilustracije 1. možemo da zaključimo da ukoliko azimut nije jednak nuli $(\Phi \neq 0)$, zvuk će ranije doći do bližeg uva. Takođe, dâ se zaključiti da je interauralno kašnjenje najveće za azimut $90^{\circ} \mathrm{i}$ autori kažu da je za prosečne dimenzije glave ono oko $0,6 \mathrm{~ms}$. Ako je frekvencija takva da je trajanje periode veće od interauralnog kašnjenja, fazna razlika signala na levom i desnom uhu predstavlja informaciju na osnovu koje se određuje pravac nailaska zvučnog talasa. Upravo je to ilustrovano na ilustraciji 3.

Međutim, Pavlovićeva tvrdi da ako je trajanje periode manje od interauralnog kašnjenja [2], što znači na dovoljno visokim frekvencijama, onda se na osnovu ITDa ne može odrediti pravac iz kog nailazi zvuk, jer različita kašnjenja mogu izazvati istu faznu razliku.

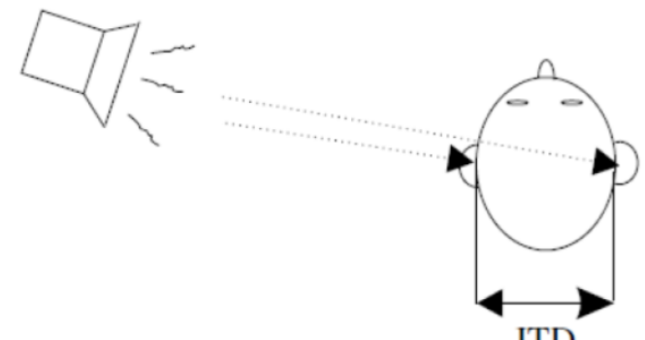

Ilustracija 3 - Vremenska razlika

Što se tiče određivanja udaljenosti izvora, naučnici tvrde da se udaljenost izvora najprirodnije procenjuje pomoću subjektivnog nivoa izvora. Kao $\mathrm{i}$ to da mogućnost za procenu velikih udaljenosti pruža promena boje tona, zbog slabljenja komponenata viših učestalosti [1] u spektru složenog zvuka. Blizinu izvora, takođe, osećamo promenom boje tona, ali je tu proces suprotan, te je zvuk pun niskih frekvencija. Bekeši tvrdi da se ktratkotrajni tonovi u blizini izvora pojavljuju sa velikom amplitudom brzine čestica. U literaturi, ova pojava se često naziva efekat blizine.

Kada je u pitanju osećaj dimenzija izvora, mora se reći da je to najneispitanija oblast binauralne lokalizacije i da sem Bekešijevog istraživanja u ovoj oblasti 1949. godine, drugih značanih pokušaja nije ni bilo. On je istraživao na sledeći način: frontalno je postavio dva izvora zvuka na rastojanju od $70 \mathrm{~cm}$, i udaljavajući se od njih proveravao osećaj rastojanja između izvora.

Iz neposredne blizine se razmak vrlo dobro ocenjivao. Udaljavajući se od izvora, razmak je postajao sve veći, pa se na $7 \mathrm{~m}$ udaljenosti činio čak $180 \mathrm{~cm}$, umesto realnih 70 $\mathrm{cm}$. Na $10 \mathrm{~m}$ odstojanja mu se činilo da radi samo jedan izvor i to u jednoj tački. Pokazao je i efekat da nam se izvori koji se nalaze iznad ili ispod horizontalne ravni posmatranja čine većih dimenzija nego kada se nalaze $u$ toj ravni. Nešto slično se može iskusiti u operskoj sali. Orkestar se iz partera čini manjih dimenzija, nego ako se sluša sa balkona, iako smo dalje od orkestra.

\section{ELEKTROAKUSTIČKA REPRODUKCIJA}

Dva glavna pravca u kojima se razvija prenos prostornih infomacija u audio sistemima su:

- binauralni koncept i

- $\quad$ stereo koncept

Može se reći da je binauralni koncept namenjen samo jednom individualnom slušaocu, a stereo je namenjen auditorijumu i omogućava percepciju prostornih informacija [3] u nekom zadatom prostoru. Binauralni koncept se zasniva na stvaranju odgovarajućih zvučnih signala na levom i desnom uhu, što podrazumeva prenos dva signala koji se reprodukciju pomoću slušalica.

Stereo sistem reprodukcije podrazumeva primenu dva ili više prostorno raspoređenih zvučnika preko kojih se reprodukuju nezavisni signali. Ograničen broj zvučnika koji se postavljaju pri reprodukciji u izlaznom akustičkom okruženju jedini su realni zvučni izvori koje slušalac može u takvim okolnostim da registruje.

Prostorne dimezije zvučne slike u stereo sistemima, sa proizvoljnim pozicijma zvučnih izvora, formiraju se kao auditivne iluzije. One se zasnivaju na psihoakustičkim fenomenima u procesu slušanja kada zvuk istovremeno stiže iz više izvora raspoređenih u prostoru.

Binauralni koncept, s druge strane, je najdirektniji pokušaj prenosa prostornih informacija jer se zasniva na oponašanju fizičkih procesa koji se odigravaju na glavi slušaoca kada je on neposredno prisutan u ulaznom akustičkom okruženju i direktno prima zvučne informacije.

Osnovu metode čini filtriranje audio signala odgovarajućim prenosnim funkcijama za azimut $\Phi$ kojim se želi definisati zadata pozicija izvora u zvučnoj slici [2]. Prenosne funkcije filtra za desno uvo HRTFФD i levo uvo HRTFФL predstavljaju funkcije fizičkih dimenzija glave i azimuta.

Njhov uticaj je za čulo sluha ključ kojim se dekoduju prostorne informacije. Za svaki željeni položaj izvora $\mathrm{u}$ zvučnoj slici koju prima slušalac potrebno je njegov signal prethodno filtrirati odgovarajućim prenosnim 
funkcijama. Na ilustraciji 4 možemo upravo šemu binauralnog koncepta, gde se ulazni signal propušta kroz filtre koji predstavljaju funkcije fizičkih dimenzija glave i azimuta i time slušalac slušajući preko slušalica dobija željene prostorne informacije zvuka.

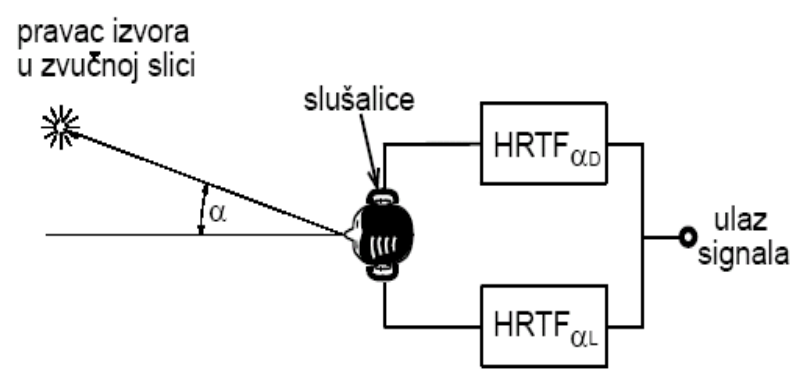

Ilustracija 4 - Šema na kojoj se zasniva binauralni koncept

Kada se tako filtrirani signali dovedu pomoću slušalica direktno u uši slušaocu, teoretski se nadoknađuje sve ono što bi slušalac inače imao, u fizičkom smislu, da se nalazi na licu mesta.

Ovakav princip se u praksi može realizovati na dva načina:

1) snimanjem pomoću uređaja koji se naziva veštačka glava ili

2) sintezom pomoću odgovarajuće predobrade pojedinih komponenti složenog audio signala.

\subsection{Reprodukcija preko zvučnika}

Rekli smo da binauralnim slušanjem tj. slušanjem na oba uha naš slušni aparat analizira zvučne pritiske sa raznih punktova u prostoru. To se može proveriti slušanjem monofonskog snimka koji nastaje tako što se u postupku snimanja signali sa jednog ili više mikfona dovode na jedan kanal i reprodukuju preko jednog zvučnika.

Jasno nam je da inteligentno slušanje o kojem smo govorili ne možemo primeniti ako su svi zvukovi koncentrisani u jednoj tački (zvučnik).

Metod reprodukcije zvuka preko velikog broja zvučnika se bazira na tome da se veliki broj mikrofona poređa na jednoj ravni ispred zvučnih izvora, a signali sa pojedinih mikrofona se pomoću jednog prenosnog sistema dovode do odgovarajućih zvučnika koji su poređani po jednoj ravni ispred slušališta.

Takav više-kanalni sistem je veoma složen i skup. Ekonomski razlozi nas teraju da prenosni kanali smanjuju na što je moguće razumniju meru [3]. Na filmu se pokušalo raditi sa 5 ili 3 kanala. Najprihvatljiviji sistem, sa akustičke i ekonomske tačke gledišta, ipak je ostao sa dva kanala, tzv. stereofonija.

Ako postavimo par zvučnika baš tako i preko oba istovremeno reprodukujemo jednake nivoe zvučnih pritisaka, slušalac neće čuti odvojene signale iz odgovarajućih pravaca, već će registrovati jedan fiktivni izvor i to u sredini rastojanja između dva zvučnika [1]. To rastojanje se inače naziva stereo baza ili širina stereo baze.
Menjamo li nivoe signala ili vreme njihovog međusobnog kašnjenja, fiktivni izvor se kreće između dva zvučnika. Ovaj efekat je osnova za stvaranje stereofonske reprodukcije preko zvučnika, pri kojoj slušalac ima iluziju prostornog slušanja.

\subsection{Reprodukcija preko slušalica}

Prava zamena zvučničkoj kontroli jeste reprodukcija preko slušalica. Jedan od razloga jeste smanjenje troškova, slušalicama postižemo reprodukciju koja nema značajnih izobličenja, a u ušima se istovremeno postiže ista maksimalna vrednost zvučnog pritiska kao i kod zvučnika.

Posebna prednost reprodukcije preko slušalica jeste ta što ne postji uticaj akustike prostorije za slušanje i što okolna buka koja nije dovoljno izolovana praktično nema mogućnost da ometa reprodukciju. Prenošenje originalne glasnosti i dinamike je isto prilično zadovoljavajuće.

Istraživanja su pokazala da je bolje koristiti reprodukciju preko slušalica nego preko loših zvučnika jer se na slušalicama lakše otkrije postojanje ometajućih šumova, nego sa nekvalitetnim zvučnicima, koji i sami unose smetnju.

Pri jednako glasnoj reprodukciji, odnos signal šum je preko slušalica $10 \mathrm{~dB}$ veći.

Nedostatak reprodukcije preko slušalica je lokalizacija virtualnih izvora „na glavi ili u glavi“. Postoji i neprijatnost, tj. zamaranje slušaoca neprekidnim držanjem slušalica na ušima.

Osnovna razlika reprodukciji preko zvučnika, jeste pojedinačno delovanje svakog uha kao samostalnog elektroakustičkog pretvarača, uz veoma mali uticaj drugog uha.

Ako stereofonski signal slušamo preko slušalica, lokalizacija virutalnog izvora je u glavi, i to na izmišljenoj liniji koja spaja oba uha. Ovu vrstu lokalizacije pravca nazivamo lateralizacijom. Pravac se određuje kao i kod reprodukcije preko zvučnika, pomoću intezitetne i vremenske razlike.

\subsection{Zona stereofonskog slušanja}

Površina kojom možemo lokalizovati virtualni izvor sa podnošljivom greškom naziva se zonom ispravne stereofonske lokalizacije. Svako pomeranje slušaoca iza ose, ka jednom od zvučnika, prouzrokuje i pomeranje fiktivnog izvora ka bližem zvučniku.

Postoji i nešto što se zove zona stereofonskog slušanja i ona definiše površinu sa koje slušalac još uvek ima utisak stereofonske reprodukcije [4], ali sa primetno netačnom lokalizacijom virtualnih izvora. $\mathrm{Na}$ ilustraciji 5 je ilustrovana zona stereofonskog slušanja i idealna pozicija slušaoca prilikom sterefonske reprodukcije zvuka. 


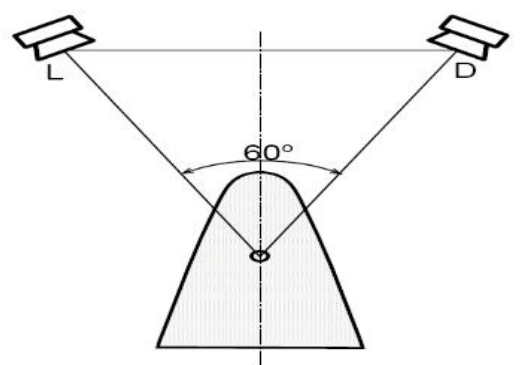

Ilustracija 5 - Zona stereofonskog slušanja

\subsection{Reprodukcija snimka načinjenog primenom veštačke glave}

Stereofonija veštačke glave možda i najvernije prenosi originalni doživljaj zvuka koji bi imao slušalac na mestu prirodnog prijema. U stanju je da prenese relativno tačno sve pravce, a iznad svih metoda, u stanju je da izuzetno reprodukuje osećaj udaljenosti izvora [1].

Za razliku od ostalih stereofonija, slušalac ima utisak da se nalazi u centru događanja. Nerešenu teškoću, međutim, i dalje čine glasovi koji dolaze frontalno, a u reprodukciji se često osećaju iznad ili iza glave.

Stereofonski snimak načinjen primenom veštačke glave, principijelno, ima smisla reprodukovati samo preko slušalica, pošto se specifične prednosti ove tehnike mogu predstaviti samo na ovaj način [4].

$\mathrm{Na}$ ilustraciji 6 je prikazana šema binauranog snimanja pomoću veštačke glave. Veštačka glava se postavi u određeni prostor i mikrofoni koji se nalaze u ušnim kanalima glave snimaju signal zvučnog izvora sa svim prostornim karakteristikama, kao i sa karakteristikama koje unosi glava, ili eventulani torzo.

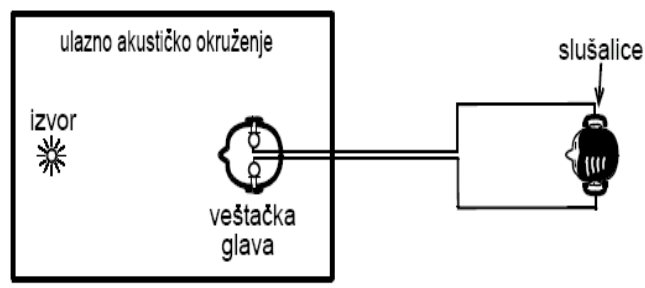

Ilustracija 6 - Šema binauralnog snimanja pomoću veštačke glave

\section{ZAKLJUČAK}

Ideja o binauralnom snimanju i reprodukciji zvuka nije nova, stara je gotovo sto godina. Međutim, tek danas, kada realnost postaje virtualna, binauralna tehnologija dobija više na značaju. Gejming, filmska i muzička industrija sve više pribegavaju binauralnom konceptu. Jedan od razloga jeste što su sadržaji sve više namenjeni individualnom slušaocu tj. ljudi sadržaj češće konzumiraju samostalno.
Bioskope su počele da menjaju striming platforme kao što su Netflix, Hulu, HBO OD. Gejming se iz igraonica i igre u LAN-u, premestio na personalne računare i samostalno igranje preko interneta. Koncerti su zbog situacije sa pandemijom počeli da se izvode online.

Ono što je novi milenijum doneo u pogledu binauralne tehnologije jeste podela mišljenja da li bi ta tehnologija trebalo da bude standardizovana ili individualizovana. Industrija želi standardizaciju dok samostalni istraživači navijaju za više individualan pristup. Standardizacija bi pomogla poređenju podataka i kasnijoj kalibraciji, a individualni pristup bi se verovatno bavio pojedinačnim problemima binauralne tehnologije.

Novi milenijum oživeo je i ideju binauralnih hedseta, $\mathrm{tj}$. kombinaciju slušalica i mikrofona. Uređaji koji postoje u ponudi su BHM III [5] od HEAD-acoustics i B \& K 41011. Kompanija Hooke takođe nudi hedset kojim može da se snima i odmah nakog toga reprodukuje na istim slušalicama.

\section{LITERATURA}

[1] I. F. S. T. Arpad Osnović, Akustika i tonsko snimanje, Novi Sad: JRT, 1990.

[2] D. Pavlović, Praktikum iz Elektroakustike, 2013.

[3] L. Gordić, Stereofonija - teorija i praksa, 2016.

[4] Višer, "Audio monitoring - sistemi za reprodukciju," Beograd, 2020.

[5] P. S, "Binaural Recording technology: A historical review and possible future developments," Acta Acoustica, 2009.

\section{Kratka biografija:}

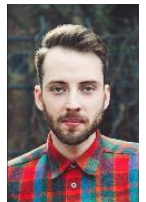

Milan Marković rođen je u Vrbasu 1994. godine. Osnovne akademske studije, na Fakultetu tehničkih nauka iz oblasti Elektrotehnike i računarstva - Energetika, elektronika i telekomunikacije, je završio 2018. godine.

kontakt: markovic.milan99@gmail.com 